\title{
2016 LEARNING REPORT ON THE IMPLEMENTATION OF THE ACCOUNTABILITY MECHANISM POLICY
}


2016 LEARNING REPORT

ON THE IMPLEMENTATION

OF THE ACCOUNTABILITY

MECHANISM POLICY 
(C) 2017 Asian Development Bank

6 ADB Avenue, Mandaluyong City, 1550 Metro Manila, Philippines

Tel +632632 4444; Fax +6326362444

www.adb.org

Some rights reserved. Published in 2017.

ISBN 978-92-9257-819-0 (Print), 978-92-9257-820-6 (e-ISBN)

Publication Stock No. TIM168490-2

DOI: http://dx.doi.org/10.22617/TIM168490-2

The views expressed in this publication are those of the authors and do not necessarily reflect the views and policies of the Asian Development Bank (ADB) or its Board of Governors or the governments they represent.

ADB does not guarantee the accuracy of the data included in this publication and accepts no responsibility for any consequence of their use. The mention of specific companies or products of manufacturers does not imply that they are endorsed or recommended by ADB in preference to others of a similar nature that are not mentioned.

By making any designation of or reference to a particular territory or geographic area, or by using the term "country" in this document, $A D B$ does not intend to make any judgments as to the legal or other status of any territory or area.

This work is available under the Creative Commons Attribution 3.0 IGO license (CC BY 3.0 IGO)

https://creativecommons.org/licenses/by/3.0/igo/. By using the content of this publication, you agree to be bound by the terms of this license. For attribution, translations, adaptations, and permissions, please read the provisions and terms of use at https://www.adb.org/terms-use\#openaccess

This CC license does not apply to non-ADB copyright materials in this publication. If the material is attributed to another source, please contact the copyright owner or publisher of that source for permission to reproduce it. $A D B$ cannot be held liable for any claims that arise as a result of your use of the material.

Please contact pubsmarketing@adb.org if you have questions or comments with respect to content, or if you wish to obtain copyright permission for your intended use that does not fall within these terms, or for permission to use the ADB logo.

Notes:

In this publication, "\$” refers to US dollars.

Corrigenda to ADB publications may be found at http://www.adb.org/publications/corrigenda 


\section{Contents}

Tables and Figures

2016 Joint Accountability Mechanism Learning Report Preparation Team

Abbreviations

Introduction

Objectives and Methodology

Findings

Sustainable Development and Climate Change Department 3

Independent Evaluation Department

Accountability Mechanism-Problem Solving and Compliance Review

5

Compliance Review Panel and Office of the Compliance Review Panel

7

Office of the Special Project Facilitator

12

\section{Common Lessons}

17

ADB's Accountability Mechanism Works

17

Awareness Building

18

Consultation, Consultation, and More Consultation 18

Implementation Focus 19

Partnership with Nongovernment Organizations and Civil Society Organizations 20 


\section{Tables and Figures}

Tables

1 ADB Operations Costs for Accountability Mechanism Cases 5

2 Subject and Frequency of Special Project Facilitator Complaints 9

$3 \quad$ ADB.org Usage Summary (Page Views) from 2012 to 2015

Figures

1 Complaints received under the Accountability Mechanism Policy, 2003 and 2012

2 Breakdown of Complaints Received by Special Project Facilitator and Compliance Review Panel under Accountability Mechanism Policy 2012

8

3 Office of the Special Project Facilitator Expenditures per Year Since 2004 


\section{Joint Accountability Mechanism Learning Report Preparation Team}

Rotating Chair of Preparation Team

\section{Team members}

Secretariat
D. Tang, chair, Compliance Review Panel and concurrently head, Office of the Compliance Review Panel (CRP)

Compliance Review Panel, Office of the Compliance Review Panel

D. Tang, chair, CRP and concurrently head

N. Ganguly, advisor

J. Miranda, compliance review officer

J. Mapilisan-Villanueva, associate compliance review coordinator

Office of the Special Project Facilitator

J. Shah, special project facilitator

J. Francis, principal facilitation specialist

M. Robidillo, consultation officer

W. Agliam, associate facilitation coordinator

Independent Evaluations Department

V. Thomas, director general (up to 12 August 2016)

W. Kolkma, director, Independent Evaluation Division 1

Sustainable Development and Climate Change Department

N. Ahmad, deputy director general, concurrently chief compliance officer

H. Gunatilake, director, Environment and Safeguards Division

N. Ganguly, advisor, OCRP 


\section{Abbreviations}

\begin{tabular}{|c|c|c|}
\hline$A D B$ & - & Asian Development Bank \\
\hline AMP & - & Accountability Mechanism Policy \\
\hline $\mathrm{CCO}$ & - & chief compliance officer \\
\hline CRO & - & complaint receiving officer \\
\hline CRP & - & Compliance Review Panel \\
\hline $\mathrm{CSO}$ & - & civil society organization \\
\hline DMC & - & developing member country \\
\hline GRM & - & grievance redress mechanism \\
\hline IED & - & Independent Evaluation Department \\
\hline NGO & - & nongovernment organization \\
\hline OCRP & - & Office of the Compliance Review Panel \\
\hline OGC & - & Office of the General Counsel \\
\hline OSPF & - & Office of the Special Project Facilitator \\
\hline SDCC & - & Sustainable Development and Climate Change Department \\
\hline SDES & - & SDCC Environment and Safeguard Division \\
\hline SPF & - & special project facilitator \\
\hline SPS & - & safeguard policy statement \\
\hline
\end{tabular}




\section{Introduction}

The Asian Development Bank (ADB) has measures in place to help promote accountability. ADB established the Accountability Mechanism - an independent forum for affected persons or communities to address their concerns and seek solutions about ADB-assisted projects, including noncompliance with ADB policies and procedures.

The Accountability Mechanism covers the Office of the Special Project Facilitator (OSPF), the Compliance Review Panel (CRP), and the Office of the Compliance Review Panel (OCRP). The OSPF holds informal consultations with affected persons to hear their complaints and seek solutions - the problem-solving phase. The CRP looks into noncompliance with ADB's operational procedures and policies leading to direct and material or likely harm to affected persons.

The ADB Accountability Mechanism Policy of 2003 (AMP 2003) was revised in 2012 (AMP 2012). The AMP 2012 made significant changes, which include (i) giving affected persons freedom of access to the compliance review function instead of necessarily going first to problem solving; (ii) appointing a complaint receiving officer (CRO) as the single entry point to receive and forward complaints to the Special Project Facilitator (SPF) or CRP Chair as appropriate; (iii) enhancing the independence of compliance review; (iv) improving efficiency such as giving the operations departments and project-level grievance redress mechanisms (GRMs) more scope for problem solving; and ( $v$ ) improving awareness and enhancing learning. 


\section{Objectives and Methodology}

The AMP 2012 requires that OCRP, OSPF, Independent Evaluation Department (IED), and the Sustainable Development and Climate Change Department (SDCC) produce a learning report every 3 years. The objective of this joint learning report is to distill ADB's experience, insights, and lessons from Accountability Mechanism operations, including the Accountability Mechanism's development impacts, benefits, and costs. It aims to assess how far the Accountability Mechanism has been able to engage stakeholders-including staff, developing member countries (DMCs), project affected persons, and civil society-in promoting accountability across ADB's operations. It also considers what insights can be generated from this process that bear significance for the task of fostering culture change through constructive dialogue and co-learning. This report attempts to capture answers to these questions.

This learning report provides an opportunity for the four offices to assess lessons learned from interaction with the Accountability Mechanism processes. In the end, the goal is to create an atmosphere of cooperation to bolster the Accountability Mechanism's role in solving problems of affected persons, addressing noncompliance with ADB policies and procedures, and promoting responsiveness to the needs of affected persons at the project development and implementation stages.

Recognizing the different institutional mandates of the CRP, OCRP, OSPF, IED, and SDCC, this learning report made use of a modular approach, allowing each office to produce findings, which were then consolidated into one report. Each of the four departments was given the flexibility to choose appropriate data collection methods and the structure of presentation of its findings.

This learning report provides a summary of the key findings from each department's assessment.

Highlighted in these summaries are each department's lessons learned, and perceived gaps and issues in the implementation of the Accountability Mechanism. Following these findings is a synthesis of lessons that are common to all four departments. 


\section{Sustainable Development and Climate Change Department}

This section describes the institutional mechanisms in place to implement the safeguard policies and the lessons from the interaction of the SDCC, operations departments, Office of the General Counsel (OGC) with the two offices under the Accountability Mechanism-OSPF and OCRP. Environmental and social safeguards are key components of ADB's accountability structure. ADB's Safeguard Policy Statement (SPS), 2009 outlines the principles and requirements that recognize and address environmental and social risks in ADB's projects and aim to improve development outcomes.

The evolution of its safeguard practices and policies over the last 30 years shows that ADB has progressively improved the framework for managing environmental and social risks. Since the SPS took effect in early 2010, ADB has further refined its internal system of checks and balances to ensure due diligence, oversight, and accountability in safeguard policy application. In particular, ADB's safeguard review procedures, set out in Operations Manual Section F1, spell out the procedures for due diligence, review, and supervision to ensure safeguards compliance and to delineate the responsibilities of the operations departments, SDCC, and borrowers.

As early as the country partnership strategy formulation stage, ADB discusses safeguards risks and issues in investment projects as well as opportunities for strengthening and using country safeguards. During the project cycle, ADB carries out project screening and categorization to determine potential impacts and risks, resources required for safeguard measures, and disclosure requirements. Project categories proposed by operations departments are reviewed and approved by the chief compliance officer (CCO). During project design and preparation, ADB reviews draft safeguard documents prepared by borrowers against applicable SPS requirements. ADB determines that the SPS policy, information disclosure, and meaningful consultation requirements are met at the Management review meeting. For category "A" projects, a safeguard policy compliance memorandum is issued by the CCO to certify each project's compliance with the SPS. Through its Project Performance Monitoring System (PPMS), ADB reviews and supervises project performance against commitments of the borrower or client and flags those projects for which compliance is unsatisfactory. Projects that trigger the SPS include an evaluation of the implementation of safeguard plans and safeguard-related covenants in the project completion reports.

ADB continues to refine its internal system for SPS implementation. In particular, ADB has defined the safeguard review procedures, set out in ADB Operations Manual section on Safeguard Policy Statement (OM F1/BP), to clearly delineate the responsibilities of operations departments and SDCC. Through its Environment and Safeguards Division (SDES), SDCC provides Bankwide oversight for the SPS, safeguard policy and capacity development, and safeguard review and operations support for projects with significant impacts (category "A" projects). SDES reports through SDCC management to ADB Management on the overall performance of safeguard implementation. The operations departments are responsible for supervising and monitoring safeguard policy implementation in ADB projects and borrowers' compliance with the SPS. Operations departments have been equipped to undertake 
safeguard due diligence, review, and supervision, and have deployed their safeguard staff to varying degrees in their respective front offices, in sector divisions, and in resident missions.

To enable the effective implementation of the SPS, ADB increased safeguard staff resources by $66 \%$ between 2010 and 2015 (from 65 to 110 staff positions). At the same time, ADB has been strengthening the capacity of borrowers and clients to manage the environmental and social risks of projects through technical assistance. Moreover, ADB and its development partners such as the World Bank group and bilateral donors are jointly undertaking projects to bring country safeguard systems toward international good practice standards.

The review undertaken by IED in 2014 confirmed that the SPS is robust, and that project categorization is functioning well.' The review also highlighted advances made in strengthening the country safeguard systems of DMCs. In addition to expanding its own safeguards staffing significantly, which is acknowledged in the report, ADB has also taken some measures to strengthen its due diligence based on IED recommendations and Management responses.

The presence of a reasonably well-functioning safeguards system in ADB may explain, to some extent, the small number of ADB projects that the Accountability Mechanism has had to review for compliance or problem solving after the SPS took effect. The Accountability Mechanism found eight projects eligible for compliance review and/or problem solving in 2010-2015 out of the 669 projects approved in that period. Only one project ${ }^{2}$ for compliance review and two for problem-solving came under the SPS. To help ensure that the number of projects coming to the Accountability Mechanism remains small and that the grievances of affected persons are effectively addressed, ADB should continue to strengthen project review, due diligence, supervision, and monitoring, as well as meaningful consultation, and should give more attention to medium- to high-risk projects.

The SPS introduced the requirement to establish project-level GRMs. These are to address the concerns and complaints of affected persons promptly, using an understandable and transparent process that should be gender-responsive, culturally appropriate, and readily accessible to all segments of the community. According to operations departments, about $80 \%$ of project review missions have reported about complaints that have been addressed to grievance redress mechanisms (GRMs).

For complaints addressed to operations department staff directly, OSPF has established, with technical support from Office of Information Systems and Technology, the Project Complaints Tracking System, an internal online portal for systematically logging, classifying, monitoring, and acting on project-specific complaints. ADB's Project Performance Management System (PPMS) also has provisions to alert project teams when a project is at risk of not complying with safeguard covenants.

SDCC carried out a survey that measured the operations departments' perception of the Accountability Mechanism based on the staff's interaction with the CRP, OCRP and OSPF. The survey questions were categorized based on the Accountability Mechanism's eight guiding principles: (i) free and active participation, (ii) open access to relevant information, (iii) fairness to stakeholders, (iv) transparency, (v) independence, (vi) efficiency and cost effectiveness, (vii) technical competence, and (viii) improvement in project quality. The survey questionnaire was sent to 65 staff from the operations departments, SDCC, and OGC, which had participated in compliance review and OSPF's problem-solving activities in the last 12 years (2003-2015), and 35 of them responded.

Survey results show that staff are generally satisfied that the Accountability Mechanism's guiding principles are being adhered to by OSPF, the CRP and OCRP. Specifically, OSPF, the CRP and OCRP are

Asian Development Bank. 2014. Safeguards Operational Review: ADB Processes, Portfolio, Country Systems, and Financial Intermediaries. Manila.

2 Another project qualified for compliance review in 2016. 
seen by the majority of the survey respondents to be generally independent, fair, open, transparent, and technically competent. A majority of the surveyed ADB staff believe that the Accountability Mechanism benefits affected persons. Nevertheless, most of the surveyed staff perceived that the Accountability Mechanism process has room for improvement in efficiency and cost reduction. Survey respondents recommended maintaining good and case-specific technical skills of the accountability mechanism office staff and consultants to further enhance the Accountability Mechanism process.

Case studies show that the cost of processing complaints, in terms of financial expense and staff time, and the cost of hiring consultants and mounting missions, can be substantial for the operations departments (see Table 1). One of the sources of inefficiency may be the divergence of opinion between Management and the CRP about the CRP findings. Inefficiencies also arise from a divergence in views on the role of the CRP, and especially to what extent the CRP may engage in policy interpretation as a fact-finding body of the Board. It has been observed that there is increasing convergence between Management and the CRP as both entities gain better understanding about each other's processes. It should be noted that the principles-based structure of the SPS includes flexibilities that allow ADB to calibrate policy application to specific project risks and impacts. Such calibration is arrived at through thorough due diligence, professional judgment, and consensus between project teams and SDES. To facilitate the Accountability Mechanism problem-solving and compliance review processes, project teams need to keep on record project-level professional judgments made in the application of the SPS.

Table 1: ADB Operations Costs for Accountability Mechanism Cases

\begin{tabular}{|l|c|c|}
\hline Project & $\begin{array}{c}\text { Mission Costs } \\
(\$)\end{array}$ & $\begin{array}{c}\text { Staff Costs } \\
(\$)\end{array}$ \\
\hline India: Mundra Ultra Mega Power Project & 72,424 & 412,807 \\
\hline $\begin{array}{l}\text { Kyrgyz Republic: CAREC Corridor 1 (Bishkek - } \\
\text { Torugart) }\end{array}$ & 74,493 & 172,713 \\
\hline
\end{tabular}

Source: ADB estimates.

A further challenge in the compliance review process has been building borrowers' or clients' ownership of Board-approved recommendations under the AMP 2003. The AMP 2012's provision requiring Management to propose remedial actions reduces this burden. This provision enables Management and the borrower or client to collaborate and to jointly develop remedial actions. Effective consultation with affected persons on remedial actions will further enhance the feasibility of such actions.

The most effective way to reduce the costs of the Accountability Mechanism processes is to effectively and promptly resolve grievances and issues on the ground. In this regard, continued strengthening of GRMs and improving monitoring of safeguards implementation, focusing on high-risk project and capacity building of borrowers and clients, are necessary.

\section{Independent Evaluation Department}

The Independent Evaluation Department (IED) did a desk review of its Accountability Mechanismrelated evaluations in the past. It has not conducted a full evaluation of the Accountability Mechanism, but has identified three safeguards-related studies that have links to the Accountability Mechanism. First, its 2006 Involuntary Resettlement Safeguards evaluation, ${ }^{3}$ briefly looked at some compliance review cases, although without independently assessing their progress and effectiveness. Second, IED reviewed 
the Southern Transport Project case in the Sector Assistance Program Evaluation of transport projects in Sri Lanka in 2012. ${ }^{4}$ And third, its 2014 Safeguards Operational Review involved a number of more recent Accountability Mechanism cases and assessed whether the issuance of the SPS had any effect on their frequency. IED presented the findings of these reports and comments on the costs and benefits of the Accountability Mechanism before presenting some of the lessons that should help reduce the need for invoking the Accountability Mechanism.

Currently, another evaluation is under way under the title of "A Real-time Evaluation of ADB's Safeguard Implementation Experience: Country Case Studies." For this evaluation, IED has selected three country experiences as case studies: Indonesia, the Kyrgyz Republic, and Sri Lanka.

The 2006 evaluation concluded that the AMP 2003 had played a role in appropriately raising the bar for safeguard compliance, beginning with ADB's first inspection - of a project in Thailand from April 2001 to March 2002, which involved environmental, land acquisition, and involuntary resettlement issues. Since then, the inspection of an irrigation project in Pakistan in 2003 and 2004 and the compliance review of a Sri Lanka project in 2005 were found to have reinforced the preoccupation of ADB staff with compliance, particularly regarding involuntary resettlement and indigenous peoples safeguards.

The specific recommendations of the Sri Lanka panel were implemented from 2005 to 2011. Annual monitoring reports found good compliance with and implementation of the recommendations, thereby implying a reasonable level of effectiveness of the process and the Accountability Mechanism at this level. In summary, while ADB's noncompliance with ADB policies, reported in the 2005 compliance review report, was significant, the CRP monitoring reports found that significant progress had been made during the 5-year monitoring period in implementing the recommendations made. Compliance review and monitoring added value to the project. ${ }^{5}$

The 2006 Involuntary Resettlement evaluation had also concluded earlier that compliance review and monitoring had added value to the projects. All the project stakeholders were found to have recognized this. The recommendations not only resulted in the projects being brought into compliance but also led to some positive changes in the government's approach to infrastructure projects.

The 2014 Safeguards Operational Review used the extent to which safeguard problems led to investigations by the Accountability Mechanism as one indicator of the effectiveness of ADB's safeguards. The review found that the SPF had registered 38 safeguard-related complaints over 2007-2014: 15 in the 3 years before 2010, and 23 in the 4-1/2 years since the period of the SPS. Five of the complaints before 2010 were assessed to be eligible, as were another five in the period from 2010 to 2014 . This indicated an overall limited level of potential noncompliance with SPS procedures by ADB, and also that there had been perhaps not much change in the level of such noncompliance with its own policies and procedures by ADB after approval of the SPS in 2009. From a wider angle, the review saw the relatively small number of complaints itself and the careful consideration given to these as part of the Accountability Mechanism as indications that the Accountability Mechanism was working well.

The IED has drawn many lessons from evaluations of safeguard implementation, which, when applied well, should prevent most of the complaints from reaching the Accountability Mechanism. Notable are those concerning the need for better preparation of safeguard plans before approval by ADB's Board of Directors (Board) of project financing, the need for intensive stakeholder/ affected person involvement,

Asian Development Bank. 2012. Sector Assistance Program Evaluation: The Asian Development Bank's Support for the Transport Sector in Sri Lanka. Manila.

5 During IED's 2016 real-time evaluation of ADB's safeguard implementation in three countries, which includes the Kyrgyz Republic and Sri Lanka, in which compliance reviews have taken place, government agencies have highlighted that many lessons were learned from these reviews. They had also become more aware of SPS requirements. 
early provision of information to affected persons and indigenous persons about projects and their environmental and social risks, and the need for good GRMs as well as close and regular monitoring of safeguard plans, sometimes by third parties.

The 2014 Safeguards Operational Review had some more specific lessons pertaining to safeguards implementation in ADB. When applied well, these should limit any growth in cost of the Accountability Mechanism:

1. Improve the quality of safeguards processing for category "B" projects, which receive less scrutiny than category "A" projects by the central safeguards unit in ADB.

2. Ensure a level of monitoring and supervision that is both sufficiently frequent and commensurate with the level of risk-for environmental category "A" projects more attention may be needed than currently given.

3. Make projects more ready for safeguard plan implementation before Board approval.

4. Disclose environmental and social monitoring reports in a timely fashion.

\section{Accountability Mechanism-Problem Solving and Compliance Review}

Complaints to the Accountability Mechanism are processed through the CRO. Depending on the choice of function selected by the complainants, the CRO forwards them to the SPF or CRP, chair.

Under the AMP 2012, OSPF and the CRP received a total of 18 complaints, five of which were eligible and 11 ineligible (data until 30 June 2016, Figure 1). The breakdown of complaints for each department by year is shown in Figure 2. Of the 11 ineligible complaints, nine were forwarded to operations departments because complainants had not addressed the issue first with the operations departments as required by the Policy. Since effectiveness of the AMP 2012, there appears to have been a drop in eligible complaints. However, reasons are difficult to pinpoint, as the number of complaints varies over time and is linked to many factors. In terms of choice of function under the AMP 2012, the numbers of complaints (13 for the SPF and 3 for the CRP) indicate that both functions are appreciated by affected persons and are approached through the $\mathrm{CRO}$ based on their needs.

Under the AMP 2003, the Accountability Mechanism received a total of 47 complaints, 20 of which were eligible, as shown in Figure 1. Of the 27 ineligible complaints, 21 were forwarded to operations departments, as the complainants had not addressed the issues first to them; 2 were procurement-related and therefore not under the mandate of the Accountability Mechanism; 2 were past the deadline for complaints ( 2 years after project closing); and 2 could not prove direct harm caused by the project. Of the 14 eligible complaints received by SPF, 7 also applied for compliance review. Four complaints requested compliance review after completing the problem-solving phase, since compliance issues were identified. Three complaints went for compliance review, as there were policy issues, and/or affected persons were not satisfied with the problem-solving process.

The paucity of complaints received by the Accountability Mechanism may be due to many reasons, including increased safeguards resources, improved implementation and capacity, ADB avoiding significant social and environmental impacts during safeguards planning, and lack of awareness on the part of affected persons. The concerned affected persons may not be aware how to file a complaint, or there may be psychological inhibitions (maybe out of fear) in filing a complaint. The recent experience of several 
Figure 1: Complaints received under the Accountability Mechanism Policy, 2003 and 2012

(as of 30 June 2016)

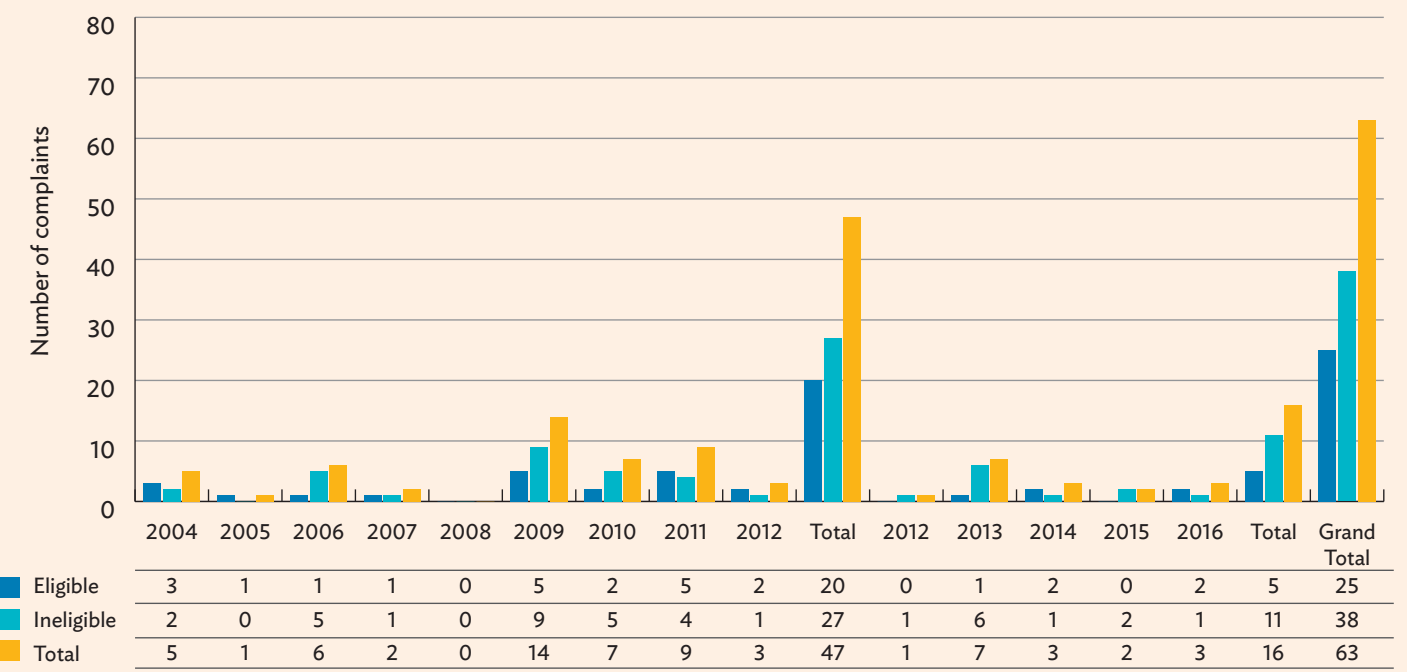

$\mathrm{CRP}=$ Compliance Review Panel, SPF=Special Project Facilitator.

NOTE: A total of 65 complaints were received of which 25 were eligible and 38 were ineligible. Two other complaints (SPF: 1; CRP: 1) that are still under eligibility assessment are not included in the above data.

Sources: ADB Office of the Compliance Review Panel, ADB Office of the Special Project Facilitator.

Figure 2: Breakdown of Complaints Received by Special Project Facilitator and Compliance Review Panel under Accountability Mechanism Policy 2012 (as of 30 June 2016)

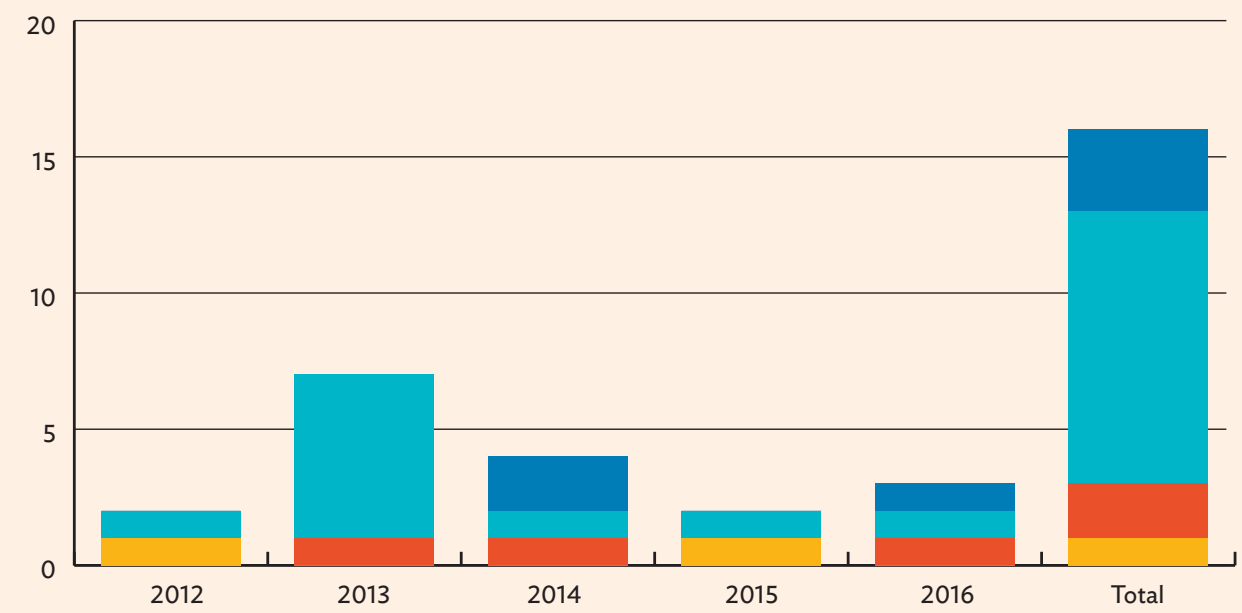

\begin{tabular}{lllllll} 
OCRP Ineligible & 0 & 0 & 0 & 1 & 0 & 1 \\
\hline OCRP eligible & 0 & 1 & 0 & 0 & 1 & 1 \\
\hline OSPF Ineligible & 1 & 6 & 1 & 1 & 1 & 10 \\
\hline OSPF eligible & 0 & 0 & 2 & 0 & 3
\end{tabular}

OCRP = Office of the Compliance Review Panel, OSPF = Office of the Special Project Facilitator. Sources: ADB Office of the Compliance Review Panel, ADB Office of the Special Project Facilitator. 
complaints to the Accountability Mechanism on a single project as well as a review of complaints over the years show that in these projects there is significant scope for improvement in environmental and social safeguards implementation. The main topics of concern under the AMP 2012 and the AMP 2003 have been resettlement, compensation, land acquisition, information, consultation, participation, agriculture, natural resources, and environmental impacts, as shown in Table 2.

Table 2: Subject and Frequency of Special Project Facilitator Complaints (as of 30 June 2016)

\begin{tabular}{|c|c|c|c|c|c|c|}
\hline \multirow[b]{2}{*}{ Subject of Complaints } & \multicolumn{2}{|c|}{$\begin{array}{l}2003 \text { Accountability } \\
\text { Mechanism Policy }\end{array}$} & \multicolumn{2}{|c|}{$\begin{array}{l}2012 \text { Accountability } \\
\text { Mechanism Policy }\end{array}$} & \multicolumn{2}{|l|}{ Total } \\
\hline & $\begin{array}{l}\text { Number } \\
\text { of Times } \\
\text { Raised }\end{array}$ & $\begin{array}{l}\text { Share of } \\
\text { Total } \\
(\%)\end{array}$ & $\begin{array}{l}\text { Number } \\
\text { of Times } \\
\text { Raised }\end{array}$ & $\begin{array}{l}\text { Share of } \\
\text { Total } \\
(\%)\end{array}$ & $\begin{array}{l}\text { Number } \\
\text { of Times } \\
\text { Raised }\end{array}$ & $\begin{array}{l}\text { Share of } \\
\text { Total } \\
(\%)\end{array}$ \\
\hline $\begin{array}{l}\text { Resettlement, compensation, and land } \\
\text { acquisition }\end{array}$ & 33 & 37.1 & 11 & 30.3 & 44 & 35.5 \\
\hline Information & 15 & 16.9 & 7 & 21.2 & 22 & 17.7 \\
\hline Consultation and participation & 11 & 12.4 & 7 & 21.2 & 18 & 14.5 \\
\hline $\begin{array}{l}\text { Agriculture, natural resources, and } \\
\text { environment }\end{array}$ & 11 & 12.4 & 4 & 12.1 & 15 & 12.1 \\
\hline Village infrastructure & 8 & 9.0 & 4 & 9.1 & 12 & 9.7 \\
\hline Community and social issues & 5 & 5.6 & 2 & 6.1 & 7 & 5.6 \\
\hline Livelihood & 2 & 2.2 & 0 & 0.0 & 2 & 1.6 \\
\hline Others & 4 & 4.5 & 0 & 0.0 & 4 & 3.2 \\
\hline Total & 89 & 100.0 & 35 & 100.0 & 124 & 100.0 \\
\hline
\end{tabular}

Source: Office of the Special Project Facilitator

The CRP looks at alleged harm to affected persons caused by ADB's noncompliance with its operational policies and procedures. This function is implemented by the independent, three-member CRP, which is supported by OCRP and reports to the Board through the Board Compliance Review Committee. The CRP reports its findings to the Board. Management is required to submit its remedial actions, based on the CRP's findings, for Board consideration. After Board approval of Management's remedial actions, Management undertakes the remedial actions to bring an ADB project back into compliance. The CRP undertakes annual monitoring for 3 years and assesses the progress of Board-approved remedial actions. The compliance review function can be divided into four distinct phases: the eligibility phase, the factfinding or investigation phase, report preparation and finalization, and monitoring of remedial actions.

OSPF provides three key services: (i) problem-solving, (ii) generic support and advice to operations departments, and (iii) outreach and in-reach to inform external and internal stakeholders about its functions and services. OSPF responds to a complaint with an intervention based on the following principles: being responsive and fair to all stakeholders; using inclusive and active multistakeholder consultation; applying open communication for clarity and access to information; introducing independent and transparent processes; intervening at minimal cost in a timely manner; avoiding project disruption; seeking explicit and formal expression of satisfaction with the intervention by affected persons; creating opportunities for long-term learning, positive impact, and institution building; and contributing to increasing both development effectiveness and operational efficiency. The OSPF process is divided into five distinct phases: eligibility, review and assessment, problem solving, implementation and monitoring, and conclusion. 
For several years now, OSPF and OCRP have been conducting both joint and separate outreach programs. First and foremost, joint outreach means cost efficiency, as both offices share the cost. In addition, through joint outreach programs, project stakeholders can see the commonalities and differences between the functions of problem solving and compliance review. However, there remains the need to inform more ADB project stakeholders and further enhance a culture of accountability among ADB staff. In the most recent ADB joint internal and external outreach programs, the Accountability Mechanism has put more emphasis on accountability principles in the work of operations departments and resident missions and of executing agencies and implementing agencies by adhering to ADB's operational policies and procedural requirements, strengthening information dissemination and meaningful consultation processes, and in particular improving the working of project GRMs.

The Accountability Mechanism website is a means to promote awareness about the Accountability Mechanism, ensure transparency and information disclosure, and reach a larger audience, including project beneficiaries. Table 3 shows the page views of web pages associated with ADB.org and the Accountability Mechanism. The number of page views from external visitors has remained more or less constant over the years for the Accountability Mechanism. This highlights the need for further strengthening outreach efforts and awareness building about the promotion of accountability in ADB projects.

Table 3: ADB.org Usage Summary (Page Views) from 2012 to 2015

\begin{tabular}{|c|c|c|c|c|c|}
\hline & $\begin{array}{l}2012-2015 \\
\text { Average }\end{array}$ & 2012 & 2013 & 2014 & 2015 \\
\hline \multicolumn{6}{|c|}{ Transparency and Other Areas Web Pages } \\
\hline $\begin{array}{l}\text { Development Effectiveness and } \\
\text { Results }\end{array}$ & 9,298 & 10,755 & 11,005 & 10,100 & 5,330 \\
\hline Accountability Mechanism & 14,444 & 14,820 & 15,426 & 14,319 & 13,212 \\
\hline Access to Information or Disclosure & 15,947 & 15,455 & 14,787 & 16,739 & 16,805 \\
\hline ADB and Civil Society & 17,798 & 20,802 & 18,093 & 14,982 & 17,313 \\
\hline $\begin{array}{l}\text { Anticorruption and } \\
\text { Integrity }\end{array}$ & 25,482 & 22,954 & 24,515 & 27,422 & 27,037 \\
\hline Safeguards & 24,836 & 21,894 & 27,148 & 26,652 & 23,648 \\
\hline Independent Evaluation & 58,690 & 56,077 & 70,583 & 68,829 & 39,270 \\
\hline \multicolumn{6}{|l|}{ All ADB.org Web Pages } \\
\hline & $16,973,514$ & $17,725,008$ & $17,876,919$ & $16,398,405$ & $15,893,725$ \\
\hline
\end{tabular}

Note: Digital Communications Team's ADB.org Usage Summery for 2013, 2014, and 2015. After the relaunch of ADB.org in November 2014, the structure of the site has been changed (rework and reduction of pages during content migration and upgrade to Drupal 7). As a result, the figures in 2015 reports represent a new baseline, and there can be no fair comparison of subsite or sector page views with previous years.

Source: ADB Department of External Relations. 
The AMP 2012 experiences related to internal complaint processing for both OCRP and OSPF for the last 3 years are listed below:

1. Direct Access to the Compliance Review Function. This gives affected persons the freedom to choose the function that would best resolve their concerns. The complainants' option of going to compliance review without going through the SPF is beneficial for compliance-related complaints, as it saves time to go through the problem-solving process first. However, once the complaint is eligible for the CRP, it can no longer avail of the benefits of quick, informal resolution through OSPF for problem solving on issues not related to compliance, which may be a disadvantage. The CRP process requires remedial action prepared by ADB Management for Board consideration and takes time to implement. For informal problem solving, it may be appropriate for affected persons to come to OSPF first, followed by the CRP. This key feature needs to be explained fully to complainants by the CRO in order to help them make informed decisions.

2. Single Entry Point for Complaints. A single entry point allows complainants to go to the function of their choice (either the SPF or the CRP). In the last 3 years, the CRO has responded promptly to complainants. The four-step CRO process can take up to 31 days (if there is a clear choice of function), which may need to be analyzed and optimized.

3. Clarifying the Cutoff Date. Having a cutoff date for filing a complaint of 2 years after loan or grant closing is seen by stakeholders as a positive step as compared with the former cutoff date of the issuance of the project completion report. The closing date is now predictable and disclosed to the public. The 2-year cutoff date gives affected persons time to study potential impacts and harm caused and is an opportunity for the stakeholders to seek solutions on their own or in partnership with the borrower.

4. Improving Efficiency. The number of OSPF steps for processing a complaint has been reduced from eight to five, and they have also been simplified. Documentation for filing a complaint is now handled by the $\mathrm{CRO}$, who provides consistency; this allows solving the problem immediately. OSPF has reduced its reliance on consultants by using ADB staff to engage with complainants and solve problems on the ground to improve efficiency and to reduce costs. Records of operations departments' costs for each Accountability Mechanism complaint were not readily available, which would have facilitated analysis of options for improving efficiency. OSPF is engaged with operations departments to help improve their problem-solving knowledge and skills. OSPF will continue to assist complainants' understanding of its review and assessment reports and the subsequent gathering of their comments and feedback after closing the complaint, for future evaluation. This initiative has proven to avert delays in the process and also to build complainants' trust and confidence in OSPF. Figure 3 summarizes OSPF's expenditures from 2004 to 2014.

The AMP 2012 and AMP 2003 experiences related to complaint resolution over the last 12 years for the CRP-OCRP and OSPF are reported separately in the next two subsections. 
Figure 3: Office of the Special Project Facilitator Expenditures per Year Since 2004

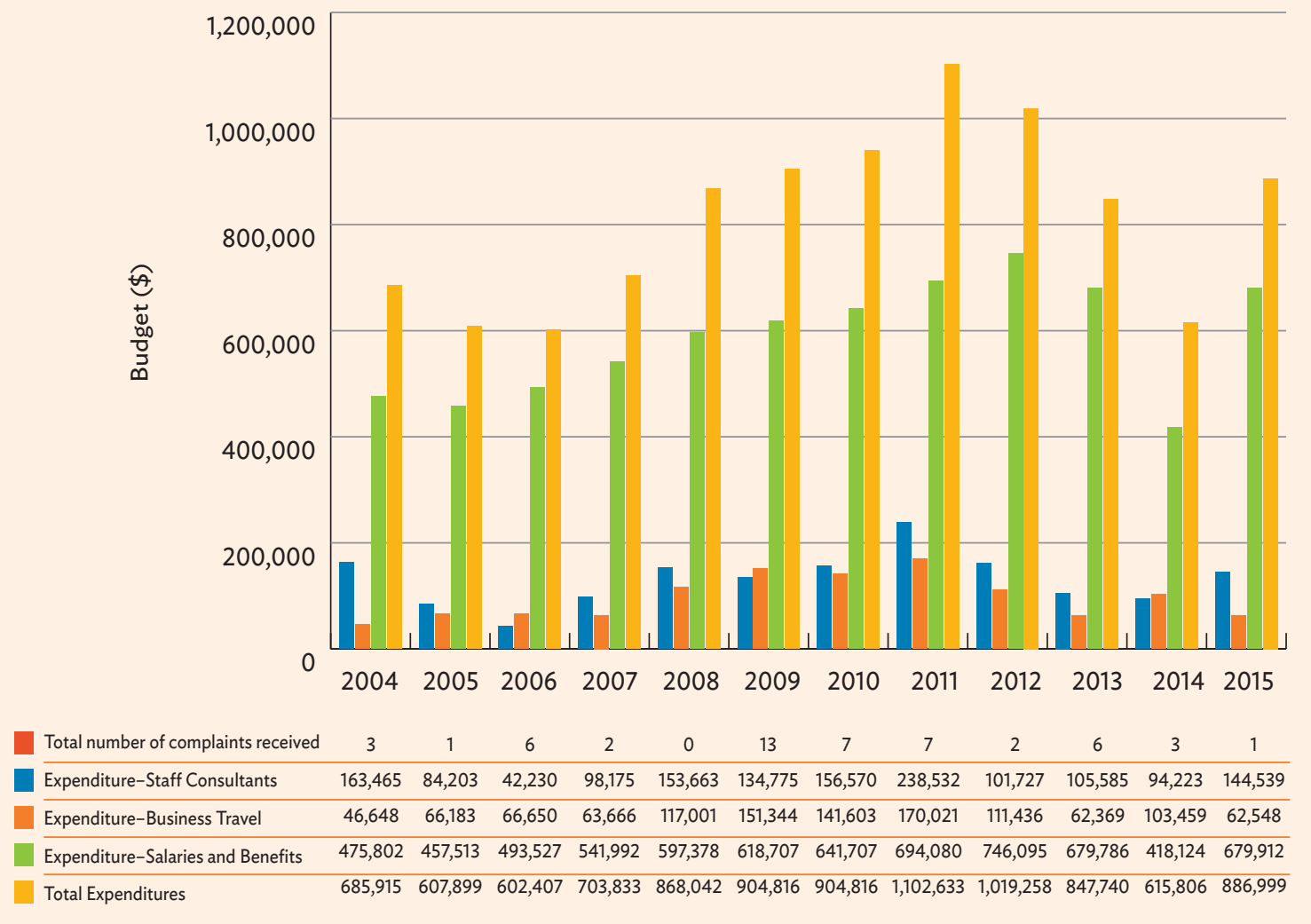

Source: Office of the Special Project Facilitator.

\section{Compliance Review Panel and Office of the Compliance Review Panel}

For this report, OCRP conducted a self-administered survey that was e-mailed to 46 respondents. These were ADB staff, borrowers, and complainants and/or their representatives who participated in a compliance review from 2011 onward. Of these, 14 ADB staff, a representative from a borrower, and three nongovernment organizations (NGOs) that were involved in filing the complaints responded. These three NGOs were Inclusive Development International, Equitable Cambodia, and the NGO Forum on ADB; all were associated with specific compliance review cases. The response from the NGO Forum on ADB, an umbrella organization with its network in the Asia and Pacific region, was based on a broad survey among its wide range of members and can be considered as representative. The questionnaire involved the following parameters or categories: (i) awareness and outreach, (ii) responsiveness to the concerns of affected persons and fairness to all stakeholders, (iii) reflecting highest professional standards in its staffing and operations, (iv) transparency and information disclosure, (v) cost effectiveness and efficiency, and (vi) conflict of interest and independence. The CRP and OCRP's findings also flow from its actual cases. A newly published report by 11 international civil society organizations (CSOs) (with global coverage) on the performance assessment of 11 independent accountability mechanisms of development finance institutions entitled "Glass Half Full? The State of Accountability in Development 


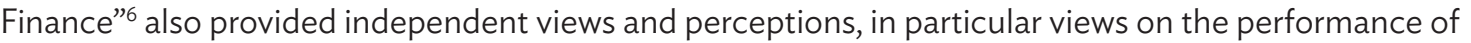
the Accountability Mechanism. The report is also based on experience gathered by the CRP and OCRP and the lessons learned from actual compliance review cases. The report is also premised on in formal dialogue with various operations departments and the experiences flowing from outreach events.

Responsiveness to the Concerns of Affected Persons. Three surveyed NGOs representing complainants as well as the report by 11 international CSOs referred to earlier and the views of CSOs from the ADB 2016 Annual Meeting in Frankfurt state that the CRP demonstrated impartiality, integrity, and competence in conducting its investigations. Finding the CRP investigation reports to be cogent and thorough, they viewed the CRP to be responsive to the concerns of the affected persons whom they represent. In the meantime, NGOs and CSOs find it difficult to deal with the requirement of making prior "good faith efforts" with the responsible operations department on the part of the affected persons to address their problem. Meanwhile, several surveyed ADB staff noted that it can occasionally become difficult to convince the borrower or client to implement proposed recommendations or to come up with concrete remedial actions. Under the AMP 2012, complainants are allowed to go directly to compliance review if they have serious issues about policy compliance and they think that it could address their concerns better. However, some surveyed ADB staff perceive that having problem solving prior to compliance review addresses the concerns of the affected persons better. On the other hand, for cases that have serious concerns about policy compliance, there seems to be a recognition that going through problem solving takes up unnecessary time.

Professionalism and Technical Standards in Staffing and Operations. Operationally, the CRP and OCRP follow the procedures outlined in the AMP 2012 and ADB Operations Manual section on the ADB Accountability Mechanism (OM L1/BP). To effectively discharge its functions, the CRP exhausts all possible fact-finding methods to come up with its findings and analysis in a compliance review. The NGO and CSO in the OCRP survey referred to previously, the 11 umbrella NGOs and CSOs representing global coverage mentioned earlier, as well as the views of NGOs and CSOs expressed in the Accountability Mechanism institutional event at the ADB Annual Meeting in Frankfurt in May 2016, all viewed the CRP's professionalism very positively. Three surveyed CSOs expressed that they were satisfied with how the CRP engaged with them and the affected persons they represented both during compliance review and monitoring of remedial actions. Nevertheless, the CRP recognizes the need to bring about further improvement in the following areas: (i) ensuring that there is systematic filing and record keeping of project files by operations departments for easy retrieval of files should there be an investigation; (ii) clarifying communications protocol among the CRP, Management, resident missions, sector divisions, and project staff; (iii) assuring staff of the confidentiality of the compliance review process; (iv) validation of findings and recommendations before finalizing reports, especially in cases where significant inputs from the government and private sector borrowers are required; ( $v$ ) implementing more frequent monitoring of remedial actions to fully and independently assess progress and problems in their implementation; (vi) more informal dialogue with relevant staff of operations departments to provide them greater awareness about the compliance review process and practices as well as lessons learned from previous compliance review cases; and (vii) implementing a more transparent mechanism for the CRP to inform Management as to when and how projects are brought back into compliance, or why if not yet.

Transparency and Information Disclosure. The CRP website (http://compliance.adb.org/) has all the relevant information and CRP reports on projects that were sent to the compliance review function. All respondent groups seem to be satisfied with how the CRP draft reports are shared and the final documents are posted and sent to the major actors in a compliance review, including in the monitoring of remedial actions. However, the surveyed NGOs and CSOs and affected persons from the India Mundra case are unsatisfied with Management concerning the preparation of remedial action plans under the

6 V. Benneker et al. 2016. Glass Half Full? The State of Accountability in Development Finance. SOMO, Amsterdam. http:// grievancemechanisms.org/resources/brochures/IAM_DEF_WEB.pdf 
AMP 2012, which is being carried out without any consultation with affected persons and the NGOs and CSOs concerned. The CRP and OCRP agree that these participatory processes, which allow for stronger inputs of stakeholders, in particular affected persons, in the draft reports are good innovations.

Cost Effectiveness and Efficiency. The CRP is of the view that it is difficult to measure cost effectiveness for compliance review, which has both external and indirect benefits. Some ADB staff respondents indicated that the compliance review process is easily triggered by complainants but seems to be costly to ADB in terms of human resources inputs, time, financial resources, and efforts to maintain a good "public image" as a responsible development finance institution. In general, the costs of remedial actions as well as of maintaining the CRP and OCRP may be considered higher than the direct and shortterm benefits that ADB may be getting as a result of having this function. However, a more balanced assessment reveals that the compliance review process has definite external and systemic benefits that vastly outweigh those that are direct and quantifiable. Even in terms of annual budget, the CRP and OCRP conducts itself in a very frugal and objective way in terms of spending its budget. In terms of annual budget, the CRP and OCRP taken together accounted for a budget of about $\$ 1.7$ million in 2016, which is less than $0.3 \%$ of ADB's overall budget for the year.

Conflict of Interest and the CRP's Independence. ADB's OGC advises Management, SPF, OSPF, CRP, OCRP, Board Compliance Review Committee, and the Board on matters relating to ADB's rights and obligations with respect to any complaint submitted to the Accountability Mechanism. All respondent groups seem to agree that the CRP carries out its mandate thoroughly, professionally, and independently, in general. In all its cases, it is important that all parties involved in the compliance review process should be free of conflict of interest-both in fact and in appearance.

Key Lessons Learned by the CRP and OCRP. Based on OCRP's review of the implementation of the AMP 2012 during the last decade, and more especially during the last few years, the following key lessons flowing out of the eligible compliance review cases have been learned:

1. Meaningful and effective consultation with affected persons at an early stage could avoid their concerns escalating into complaints.

2. Adequate consultation with the complainants and affected persons will ensure the acceptability and the effectiveness of the proposed remedial action.

3. Active and systematic supervision of sensitive projects is necessary to effectively identify and resolve problems.

4. Compensation for affected persons needs to be timely and based on sound valuation methodologies.

5. The GRM established at the project level needs to be accessible, reliable, and transparent.

6. Accurate baseline data and study are critical for effective design and implementation of mitigation measures as well as the post monitoring of impacts.

7. Legal advice to the CRP should be fully separate from the legal advice given to Management and project operations. 


\section{Office of the Special Project Facilitator}

The Office of the Special Project Facilitator conducted a review of its experiences before and after implementation of the AMP 2012. Since the effectivity of the AMP 2012, the SPF has received $14^{7}$ complaints, with 3 found to be eligible. Of the ineligible complaints, nine ${ }^{8}$ were forwarded to the operations departments, because either the complainants had yet to address the problem to the operations department, or the operations department's efforts to address the concerns were under way, as required by the AMP 2012. Under the Accountability Mechanism 2003, OSPF received 40 complaints, 14 of which were eligible. Several ineligible complaints resolved by the operations departments over the years have shown that raising a complaint attracts attention, even if the consultation process is not pursued.

Because of the paucity of eligible complaints under the AMP 2012, this report combines and highlights lessons and insights over the last 12 years. As the number of eligible complaints received by the SPF over the last 12 years is very small (17 out of more than 1,800 projects), ${ }^{9}$ the lessons are case-specific and not necessarily applicable to ADB projects as a whole. The 17 eligible complaints and experiences highlight the importance of the following nine topics for improving implementation quality and development effectiveness:

1. Building Partnerships. While working with the operations departments, resident missions, and NGOs on each complaint, OSPF has found partnerships and mutual respect among stakeholders to be useful in resolving conflicts. These partnerships bring about a sense of ownership and accountability, which makes their collective work more fruitful and successful.

2. Information, Consultation, and Participation. If meaningful consultations that include information sharing, regular involvement, communication with project beneficiaries, and resolving conflicts quickly are carried out, the probability of complaints to the Accountability Mechanism will be lower. Even if there is a complaint, chances are that it will be resolved faster because of the trust and respect built by regular consultation.

3. Safeguards Implementation. Environmental and social safeguards-related topics account for $47 \%$, with information, consultation, and participation contributing $33 \%$ of the complaints (Table 1). Translating Management plans concerning safeguards into action by executing agencies and contractors during safeguards implementation is where problems are encountered. As evidenced by Accountability Mechanism complaints, ADB policies such as awarding compensation at replacement value for land acquisition, compensation for structures to nontitleholders (squatters), and restoration of livelihoods of affected persons are challenging for executing agencies. Deficiencies observed in Accountability Mechanism cases include inadequate understanding of policies, poor planning and financing, lack of records, inefficient and congested legal systems, reliance on consultants with limited ADB supervision, and inadequate capacity.

4. Project Implementation. Limited capacity of clients for project implementation is a contributing factor to complaints, and needs to be strengthened. In addition, incomplete or inadequate implementation agreements lead to disputes. This is especially so in the case of projects that are sensitive and/or have significant resettlement, compensation, or land issues as discussed above.

5. Conflict Resolution Experience. Delays in taking action to resolve conflicts occur due to lack of training and experience of the executing agencies. Instead of dealing with complaints immediately and taking action, conflicts are allowed to fester and eventually become intractable. Such delays lead

As of 30 June 2016, one complaint was still under eligibility assessment.

The tenth complaint was ineligible because of lack of new evidence.

Estimated by using the number of projects under implementation in 2004 and adding new projects approved every year until 2014 
to increased costs for everyone and, more importantly, pose disruptions in the livelihood and income of beneficiaries.

6. Recognition and Participation of NGOs and CSOs. NGOs and CSOs often act as intermediaries between a project and affected persons. Of the 17 eligible complaints received by the SPF since 2004, NGOs were vital in representing communities in bringing complaints to the Accountability Mechanism in more than $50 \%$ of the cases. NGOs working particularly with communities in a project area are familiar with its residents and can provide valuable information about local conditions and community priorities. They need to be integrated during project preparation and implementation.

7. Grievance Redress. While ADB projects have developed GRMs in projects when required, they are not always effective in practice. Tailoring the GRM to the unique operational environment is vital, as is the training and capacity development of staff involved in the process. ADB supervision support across sectors needs to be increased to review GRMs as well as safeguards implementation.

8. Accountability Mechanism as the Last Resort. Over the last 12 years, 30 of the 54 complaints (56\%) received by the SPF were declared ineligible because the complainants had not made prior good faith efforts to address their concerns to the operations departments. Complainants' decision to prematurely elevate their concerns to the Accountability Mechanism indicates lack of awareness about the Accountability Mechanism, the role of the operations departments and resident missions in problem solving, and the Accountability Mechanism being the last resort.

9. Advisory Function of OSPF. OSPF's internal challenge is to combat the staff perception that the Accountability Mechanism is only for solving complaints after they arise. Instead, OSPF should also be seen as a resource for generic advisory services to support improving project design and implementation, as mandated by the policy. ${ }^{10}$ The feedback and lessons from OSPF strengthen the internal problem-solving capacity of the operations departments for complaint handling. OSPF in the past 12 years has collated and integrated internal and external experiences in problem solving with the intent to improve and strengthen the internal problem-solving activities of the operations departments.

Though the process of complaint handling may be somewhat uncomfortable, it does help stakeholders to work and communicate better with each other for better results. Over the past 12 years, OSPF has helped to resolve affected persons' complex issues at the operations level through consultations, facilitation, and negotiations. OSPF intervention is mostly welcomed by operations staff, borrowers, NGOs, and CSOs, as it allows all parties to resolve issues amicably. Going forward, OSPF will work with the operations departments to encourage consideration of the lessons discussed in this report. This will ensure that the potential affected persons are on the radar from the beginning and that there are plans for addressing their complaints during implementation. OSPF's goal is to position itself as a facilitator to help enhance project impact and institutional effectiveness rather than being an additional administrative burden on projects. 


\section{Common Lessons}

Broadly, things have changed for the better, both within and outside ADB, over the last 12 years. ADB and its stakeholders are now better aware of accountability, transparency, and governance and are taking them seriously. ADB's experience across four departments in dealing with implementing the AMP 2012 and the AMP 2003 point to the following common lessons.

\section{ADB's Accountability Mechanism Works}

The review of complaints, outcomes, and perception survey of staff and stakeholders, in particular NGOs and CSOs, indicates that the Accountability Mechanism process enhances the development outcomes of ADB projects. The AMP 2012 provides direct access to compliance review, which has been utilized by affected persons three times since the effectiveness of the policy. The operations departments acted on most complaints that were ineligible for the Accountability Mechanism, which shows that raising a complaint with the Accountability Mechanism attracts attention, leading to solutions of the original problem, even if ADB's role in the complaint was not corroborated and the full Accountability Mechanism process was not pursued. A review of eligible case documents shows that the Accountability Mechanism in those cases has contributed to better outcomes in the form of resolution of the complaint, encouraged legislative reforms, and enhanced capacity building, and has resulted in improved compensation packages for the affected persons. In a wider sense, the Accountability Mechanism helps maintain a strict application of ADB's safeguards by providing incentives and/or acting as a deterrent.

The Accountability Mechanism cases and the associated remedial actions documents reflect that compliance review and problem-solving processes provide benefits to households affected by ADBassisted projects. Accountability Mechanism actions by the CRP and OSPF have helped promote legislative reforms (e.g., land acquisition in Sri Lanka and Indonesia) and cofinancing of infrastructure improvements for the betterment of households and communities (Cambodia).

Overall, the Accountability Mechanism process has contributed to strengthening procedural policy compliance with the SPS. ADB staff perceive that the Accountability Mechanism process, for both compliance review and problem solving, provides broader benefits to relevant stakeholders and that OSPF and the CRP adhere to their guiding principles such as fairness, openness, transparency, and technical competence. Nevertheless, perceptions from staff and NGOs and CSOs and cost analysis indicate that the Accountability Mechanism process has room for improvements in efficiency. Staff perceptions also suggest that, while adhering to the safeguard principles, application of innovative practices by staff in the project should not become impaired. 


\section{Awareness Building}

Under the AMP 2012 (until 30 June 2016), the Accountability Mechanism received 18 complaints," five of which were eligible (three problem-solving cases and two compliance review cases). Under the Accountability Mechanism 2003, the Accountability Mechanism received a total of 47 complaints, of which 20 were eligible (14 problem-solving cases and six compliance review cases). Most of the ineligible complaints were forwarded to operations departments, as the complainants had not consulted with them first, as required by the Policy. This, along with feedback from NGOs and CSOs, suggests that awareness of the Accountability Mechanism as the last resort for affected persons is not always clear. A review of the Accountability Mechanism website suggests that efforts are needed to ensure that stakeholders can easily access the Accountability Mechanism, view information about the policy and its operating procedures, understand how to file a complaint, and see the progress of pending cases. Similarly, the Accountability Mechanism cases exemplify the need to make the project proponents (executing agencies and implementing agencies) aware of ADB's procedural and policy requirements from the very beginning.

A staff perception survey indicates that the operations departments and the project teams as well as resident missions need to fully appreciate that problem solving and compliance review are two distinct but complementary functions of ADB's Accountability Mechanism. Such awareness will further enhance the effectiveness of the Accountability Mechanism process. The operations departments and resident missions are the frontline entities for promoting accountability to mitigate problems before they escalate. In a recent Accountability Mechanism outreach event, one implementing agency participant commented: "very good mechanism; it should be included in the project document and made clearer during project negotiations." These lessons all point toward the benefits of greater awareness raising and capacity building, and improved outreach.

In response to internal needs and external comments, efforts have been made to make the Accountability Mechanism website more comprehensive and coherent in accordance with the AMP 2012. The main page now provides links to the AMP 2012, Information Packet, and various translations; ${ }^{12}$ a centralized publications page; and a single Filing a Complaint page containing information in user-friendly format regarding who can file, where to file, what to state (complaint form, language, contents), and exclusions. Other changes involve updating information to reflect the changes under the AMP 2012, making headings used for the two functions consistent and providing links to the Accountability Mechanism Facebook page and Independent Accountability Mechanisms Network website hosted by the Accountability Mechanism. Accountability Mechanism would be carrying forward these efforts in the future years.

\section{Consultation, Consultation, and More Consultation}

The review of the Accountability Mechanism cases shows that most of the complaints have listed a lack of adequate and meaningful consultation as a trigger. This has not changed over the past 12 years, and it continues to be an issue often underlying new complaints received by the operations departments. Deficiencies in information, consultation, and participation during project design and implementation have been raised as issues in almost all complaints. The affected persons have complained about not having been fully informed of their options in a way that enabled them to make

As of 30 June 2016, two complaints were still under assessment by SPF and CRP.

2 The AMP 2012 is available in English and 11 DMC languages, namely, Bahasa Indonesia, Chinese, Hindi, Khmer, Lao, Nepali, Russian, Sinhala, Tamil, Urdu, and Vietnamese. It will also be available in Bangla, Dari, and Pashto by December 2017. 
informed decisions. Consultation and participation of affected persons would have surely made a difference for the Accountability Mechanism cases, and could have prevented at least some complaints. Where Accountability Mechanism complaints lead to action plans, they should also be prepared based on meaningful communication and effective consultation with the affected persons, although that is not always easy, particularly when the affected persons are widely dispersed.

Building the borrower or client ownership, through consultation, for action plans prepared in the Accountability Mechanism process was a major challenge for the CRP under the AMP 2003. The current AMP 2012 requirement for ADB to develop an action plan jointly with the borrower or client reduces this burden and has enhanced Management's and the borrower's or client's collaboration on the action plan. The enhanced collaboration between Management and the borrower/client on the action plan has improved the implementability of action plans. This is also crucial for ensuring that problems are resolved to the satisfaction of affected persons.

The major subjects of the Accountability Mechanism complaints since 2003 are resettlement, compensation, and land acquisition; and adverse environmental impact. These subjects both require effective and active stakeholder consultation during project design and implementation. If meaningful consultations, which include improved information sharing, regular involvement, and communication with project beneficiaries, and resolving conflicts quickly, are carried out in a timely fashion, the probability of complaints should be less. Even if there is a complaint, chances are that it will be resolved faster because of the trust and respect built from regular consultation. With meticulous efforts to plug these deficiencies, the objectives of meaningful consultation will be achieved in coming years.

\section{Implementation Focus}

Better communication between ADB staff and OSPF, the CRP, and OCRP about the Accountability Mechanism policies and procedures can further enhance the effectiveness of the Accountability Mechanism process. There is a need for regular dialogue on ADB's Accountability Mechanism between ADB staff and Management, to further enhance the functioning of the Accountability Mechanism. It would also be helpful to reach a better understanding among internal stakeholders on their respective roles in matters of policy interpretation (as opposed to fact-finding) under the Accountability Mechanism policy. The negative perception from both sides of the Accountability Mechanism as looking only at problems needs to be changed. Such dialogue would hopefully result in ADB staff perceiving the Accountability Mechanism process as an opportunity for improving project design and implementation and avoiding mistakes in the future.

Recent Accountability Mechanism cases established that a poorly functioning GRM was part of what triggered the complaint. ADB staff should be further incentivized in assisting the borrower in establishing a well-functioning GRM in each project with environmental and social risks. ADB should showcase projects where the GRM is functioning well and the consultation process has led to resolution of affected persons' concerns. These actions will generate confidence, and ADB staff may be encouraged to follow such good practices to achieve better project outcomes, as well as to avoid complaints. Based on the findings of Accountability Mechanism cases, safeguards implementation performance can be further improved.

To generate positive outcomes from compliance review cases and to ensure that the process proceeds in a smooth and independent way, legal advice to the Accountability Mechanism team should be separated in a real sense from the legal advice given to Management and project operations. To this end, OGC has issued guidelines that provide for the creation of separate teams to provide legal advice to the various internal stakeholders involved in problem solving or compliance review. 
By working closely with the operations departments, resident missions, and external stakeholders, the Accountability Mechanism can build a relationship to promote culture change during implementation. Similarly, all relevant departments in ADB should continue raising awareness on safeguards and further improve internal systems for due diligence during planning and implementation. This is a common task for improved development effectiveness. Through better supervision efforts, dialogue between Accountability Mechanism and ADB's operations departments, we can achieve enhanced outcome in the future.

\section{Partnership with Nongovernment Organizations and Civil Society Organizations}

The Accountability Mechanism cases suggest that close relations of ADB with NGOs and CSOs in the borrowing countries will have benefits for the functioning of the Accountability Mechanism and GRMs and may well reduce the likelihood of safeguard complaints NGOs and CSOs have played critical roles in the implementation of the Accountability Mechanism Policy. Of the 25 eligible Accountability Mechanism complaints, NGOs and CSOs were involved in bringing complaints in more than $50 \%$ of the cases. Some took on major roles as complainants' advisors, facilitators, representatives, or intermediaries or merely as observers to ensure fairness in the process. Therefore, ADB needs to enhance its dialogue with NGOs and CSOs to promote trust and partnership building. They are often the conduits for channeling urgent concerns of the affected persons. ADB's Accountability Mechanism has increased its outreach activities to build relations with international organizations, the independent accountability mechanisms of other multilateral development banks and bilateral development agencies, and local and regional NGOs and CSOs. This has resulted in increased internal and external partnerships during the Accountability Mechanism Policy implementation period. ADB needs to increase CSOs and NGOs partnership going forward. 


\section{Learning Report on the Implementation of the Accountability Mechanism Policy}

The Accountability Mechanism Policy 2012 requires the Compliance Review Panel, Office of the Compliance Review Panel, Office of the Special Project Facilitator, Independent Evaluation Department, and Sustainable Development and Climate Change Department to produce a learning report every 3 years. This first learning report provides a summary of each department's key findings, lessons learned, and perceived gaps and issues in the implementation of the Accountability Mechanism.

\section{About the Asian Development Bank}

ADB's vision is an Asia and Pacific region free of poverty. Its mission is to help its developing member countries reduce poverty and improve the quality of life of their people. Despite the region's many successes, it remains home to a large share of the world's poor. ADB is committed to reducing poverty through inclusive economic growth, environmentally sustainable growth, and regional integration.

Based in Manila, ADB is owned by 67 members, including 48 from the region. Its main instruments for helping its developing member countries are policy dialogue, loans, equity investments, guarantees, grants, and technical assistance. 